\title{
Erratum to: HPLC Determination of Bioactive Sulfur Compounds, Amino Acids and Biogenic Amines in Biological Specimens
}

\author{
Antonio Francioso, Sergio Fanelli, Daniele Vigli, Laura Ricceri, \\ Rosaria A. Cavallaro, Alessia Baseggio Conrado, Mario Fontana, \\ Maria D'Erme, and Luciana Mosca
}

\section{Erratum to:}

Chapter 42 in: D.-H. Lee et al. (eds.), Taurine 10, Advances in Experimental Medicine and Biology 975, DOI 10.1007/978-94-024-1079-2_42

The graph of original figure 12 should be replaced with the graph of Figure 8 and original figures 9 to 12 should be renumbered as Figures 8 to 11 .

The updated online version of this chapter can be found at DOI 10.1007/978-94-024-1079-2_42

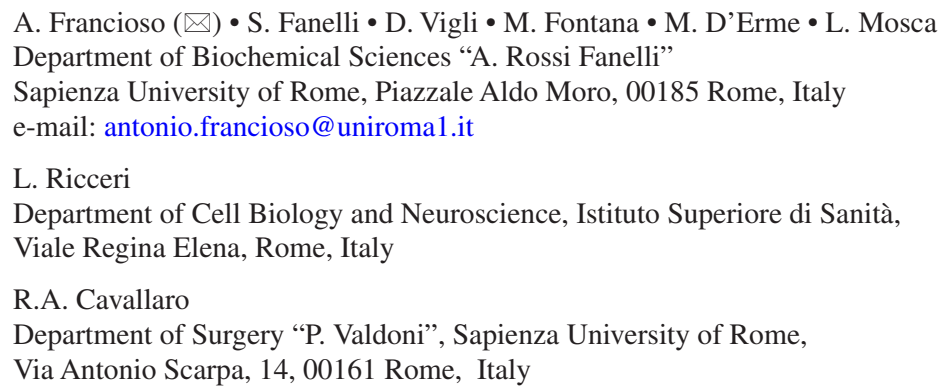

